http://kitaibelia.unideb.hu/

ISSN 2064-4507 (Online) • ISSN 1219-9672 (Print)

(C) 2015, Department of Botany, University of Debrecen, Hungary

20 (1): 150-156.; 2015

DOI: $10.17542 /$ kit.20.150

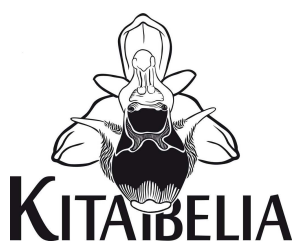

\title{
A Crepis mollis (Jacq.) Asch. subsp. hieracioides (Waldst. \& Kit.) Domin újrafelfedezése Magyarországon
}

\author{
BAUER Norbert* \& SOMLYAY Lajos \\ MTM Növénytár, H-1476 Budapest, Pf. 222; * bauer@bot.nhmus.hu

\section{Rediscovery of Crepis mollis (Jacq.) Asch. subsp. hieracioides (Waldst. \& Kit.) Domin in Hungary}

\begin{abstract}
Crepis hieracioides ( $=$ C. mollis subsp. hieracioides) was described from the Bakony Mts. (Western Hungary) by Pál Kitaibel more than 200 years ago. His record has been the single one of this taxon from the territory of present-day Hungary thus far. In the second half of the $20^{\text {th }}$ century this taxon was either reported as 'extinct' or was plainly ignored in the Hungarian literature. This paper reports about the recent rediscovery of $C$. mollis subsp. hieracioides in the Bakony Mts., specifically in the 'Bakonyalja' region (Devecser: Széki-erdő). The habitat is characterised, and the regional phytogeographical significance of this taxon is emphasised.
\end{abstract}

Keywords: Bakony Mts., Bakonyalja, Crepis mollis, C. succisifolia, C. hieracioides, flora, Hungary, Kitaibel

Összefoglalás - A Crepis hieracioides-t (= C. mollis subsp. hieracioides) Kitaibel Pál írta le a Bakonyból több mint 200 évvel ezelőtt. A mai napig ez a taxon egyetlen adata Magyarország jelenlegi területéről. A második világháború utáni flóraművek a magyar flórából kihaltként említik, illetve több összefoglaló műben már nem is szerepel. Jelen közlemény a növény magyarországi (Bakonyalja, Devecser: Székierdő) újrafelfedezéséről számol be, jellemzi a termőhelyét, és hangsúlyozza a taxon növényföldrajzi jelentőségét.

Kulcsszavak: Bakony-hegység, Bakonyalja, Crepis mollis, C. succisifolia, C. hieracioides, magyar flóra, Kitaibel Pál

\section{Bevezetés}

Közleményünkben a Crepis mollis (Jacq.) Asch. subsp. hieracioides (Waldst. \& Kit.) Domin magyarországi újrafelfedezéséről számolunk be. A növényt Magyarország jelenlegi területén eddig csak Kitaibel Pál gyüjtötte, egyetlen alkalommal a Bakonyban, s az „Icones”-ben (WALDSTEIN \& KitAiBeL 1802) Crepis hieracioides néven, a tudományra új fajként írta le. JÁVORKA (1924-1925) és BABCoCK (1947) a C. mollis (Jacq.) Asch. alá vonták, a későbbi szakirodalomban pedig annak alfajaként tárgyalták, többnyire subsp. succisifolia (All.) Dostál néven (Dostál 1950, GReUTER 2006). Jóllehet AlLIONI (1785) Hieracium succisaefolium-a régebbi a Kitaibel-féle fajnévnél, alfaji rangon Domin (1936) kombinációja prioritást élvez, amint az a nemzetséggel foglalkozó újabb szakmunkákban (DoSTÁL 1989, ONDREJOVÁ 1989, TURISOVÁ 2002) is szerepel.

A Crepis mollis elterjedésének súlypontját, az Alpok, a Nyugati-Kárpátok és környező középhegységek jelentik, de a Pireneusoktól a Balti-tenger partvidékéig előfordul, 
szórványosan Angliában, a Balkán-félsziget hegyvidékein és a Keleti-Kárpátok néhány pontján is megtalálható (JÁVORKA 1924-1925, MEUSEL \& JäGER 1992). A kopasz hajtású C. mollis subsp. hieracioides GREUTER (2006) alapján valamivel szűkebb elterjedésű, kifejezetten közép-európai hegyvidéki areával.

Az eddigi egyetlen, hazánk jelenlegi területéről származó adata a Kitaibel-féle példányon (BP: Herbarium Kitaibelianum, XXVII/16) alapul (JÁVORKA 1926). A példány cédulaszövege ("III. 50. Caulis pentagonus. Folia radicalia ovato-oblonga, sinuato-dentata, in petiolum attenuata: caulina sessilia ovato lanceolata aut lanceolata summa subintegerrima ... In sylva Bakon inter Városlőd et Nagy Vásony Julio"] alapján a növényt valószínúleg a Kab-hegy tömbjében gyűjthette 1799. július 5-7. között (CEU: 8971 vagy 8972). Útinaplója szerint ötödikén Városlőd közelében, a Kislődi-völgy („Kislőder Thal”), Kislődi-hegy („Kislőder Berg”), Mészégetők („Kalkbrennen”) és az üveghuták („Glasshütte”) környékén botanizált. Július hatodikáról nincs feljegyzés, hetedikén a Nagyvázsony környéki mészkőről, a bazaltból álló Kab-hegyről és víznyelőiről ír, kevés botanikai adattal (GomBocz 1945). Az útinaplóban a Crepis hieracioides-re nincs utalás. A növényt Kitaibel valószínűleg herbáriumában azonosította új fajként, lelőhelyét a taxon leírásakor közölte (WALDSTEIN \& KITAIBEL 1802). Megjegyezzük, hogy a berlini Willdenow-herbáriumban is van egy példány Kitaibel gyújtéséből (RöPERT 2000), amelyet BABCOCK (1947) is citált.

A Kitaibel-féle bakonyi adatot JÁVORKA $(1924-1925,1937)$ és RÉDL (1942) még idézték, a második világháború utáni szakirodalomban azonban a fajt Magyarországról már kihaltnak, vagy feltehetően kihaltnak tekintették (JÁVORKA \& Soó 1951, Soó 1970, MEUSEL \& JÄGER 1992, Greuter 2006), mások (HortobágYi 1955, Soó \& KÁRPÁti 1968, Simon 1992, PENKSZA \& SZERDAHELYI 2009) meg sem említették.

\section{Eredmények}

2014. június 6-án a devecseri Széki-erdő egy erdővel mozaikos üde gyepterületén, a Nádasrét - Rák-sík térségében a Crepis mollis subsp. hieracioides virágzó egyedeire figyeltünk fel (CEU: 8871.1). A megtalált populáció nagysága mintegy 100 tőre tehető, az egyedek egy nagyjából 1 hektáros területen szórványosan mutatkoztak. A növény előkerülését herbáriumi példányok és genetikai minták gyüjtésével dokumentáltuk. A bizonyító példányok az MTM Növénytára „Herbarium Carpato Pannonicum” gyüjteményében és a Debreceni Egyetem Növénytani Tanszékének herbáriumában kerülnek elhelyezésre.

A Széki-erdőben a növény enyhén nádasodó kiszáradó-láprét jellegű gyepben él, amelyben domináns a Molinia arundinacea. Az élőhelyfolt számos további értékes növényfajt őriz, pl. Carex panicea, Dactylorhiza incarnata, Gymnadenia conopsea, Lathyrus pannonicus, Platanthera bifolia, Schoenus nigricans, Scorzonera humilis, Selinum carvifolia, Succisa pratensis, Veratrum album. A réten tömeges az Allium suaveolens. A szomszédos erdőfoltokban és gyepekben Gentiana pneumonanthe, Hemerocallis lilio-asphodelus, Iris sibirica, Daphne mezereum, Listera ovata, Trollius europaeus és más ritkaságok élnek.

A gyep a felmérés idején üdének, megfelelő vízellátottságúnak tűnt. A szakirodalmi adatok alapján a faj agyagos talajokon kialakuló, inkább oligotróf üde réteken, magaskórósokban él (OBERDORFER 1949). A montán jellegü üde rétek, súlypontosan a Trisetum flavescens gyepek (Polygono bistortae-Trisetion flavescentis), egyik fontos differenciális eleme (HUNDT 1961, DiERSCHKE 1981, ElLENBERG 1996, BLAŽKOVÁ \& CHYTRÝ 2007, BuCHWALD et al. 2007). Előfordulási adatai a fajgazdag extenzív kaszálórétektől, a hegyi jellegű üde réteken, magaskórósokon át az alhavasi gyepekig számos élőhelytípusból (pl. Nardetum, montánabb jellegű Arrhenatheretum, Trollius europaeus-Polygonum bistorta magaskórósok, montán félszárazgyepek, Festucion carpaticae szubalpin gyepek) ismertek (SZAFER et al. 1925, PAWLOWSKI et al. 1960, HENDRYCH 1968, PASSARGe 1969, JAROLÍMEK \& ŠibíK 
2008, HEGEDÜŠOVÁ et al. 2012). A széki-erdeihez hasonló Molinion vegetációtípusokból is jelezték (BALATOVA-TulacKOVA 1996, HAVLOVÁ 2006). Természetes élőhelyei közé tartoznak a változó vízellátottságú, fényben gazdag, felnyíló erdők is (MEuSEL \& NIEMANN 1971, MEUSEL \& JÄGER 1992).

aktuális előfordulás, Devecser: Széki-erdő / new record

Kitaibel Pál adata (1799) / Data of P. Kitaibel from 1799

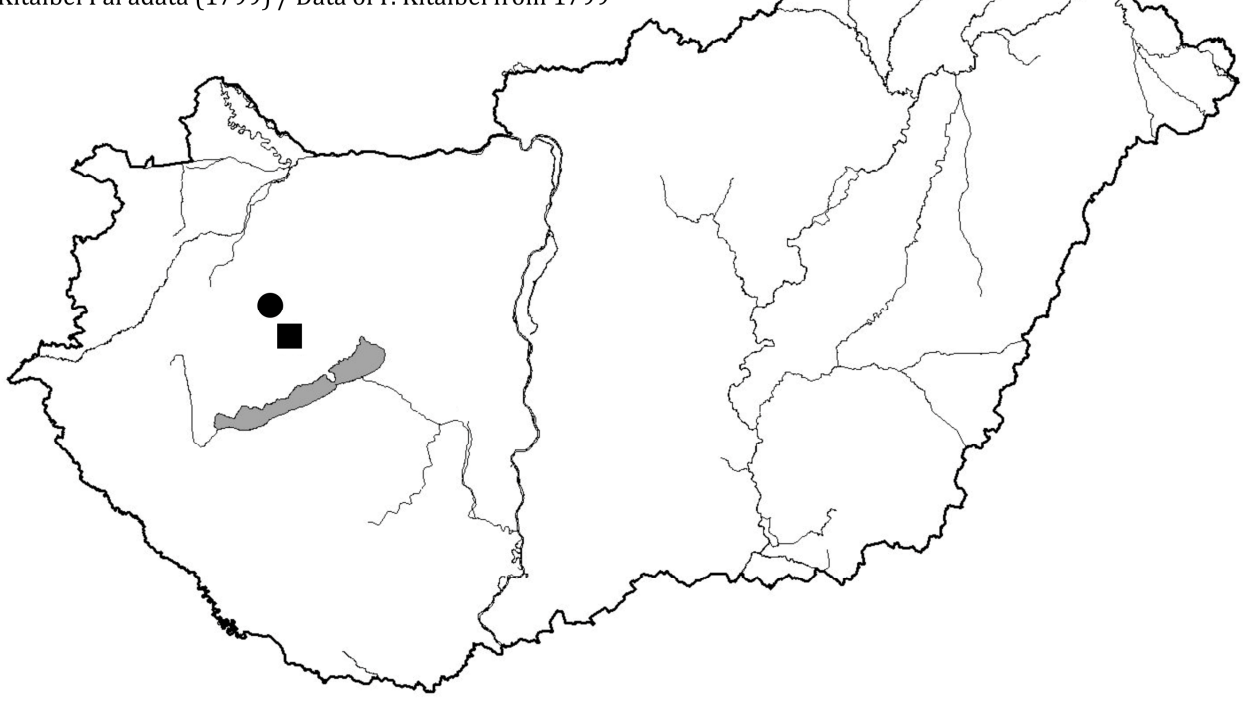

1. ábra A Crepis mollis subsp. hieracioides elterjedése Magyarországon.

Figure 1. Distribution of Crepis mollis subsp. hieracioides in Hungary.

A növény előfordulása a Széki-erdőben, a terület vegetációjának és fajgazdagságának ismeretében nem meglepő, hiszen itt, a fent említett fajokon kívül, sok más, hasonló jelentőségű és elterjedésű, közép-európai montán elem előfordulása ismert, például Buphthalmum salicifolium, Tephroseris longifolia (TALlós 1959), Hypericum barbatum, Aconitum variegatum (BAUER 2009a, b). A Crepis mollis subsp. hieracioides növényföldrajzi jelentősége e fajokhoz mérhető, flóránk montán reliktumának tartjuk. Jóllehet Soó (1970) szerint hazánkban ephemerophyton, azaz ritkán, időszakosan megjelenő növény, ezt a nézetét semmivel nem támasztja alá. A C. mollis Európa több országában, még elterjedése centrumában is visszaszorulóban lévő (MEUSEL \& JÄGER 1992, SCHNITTLER \& GÜNTHER 1999) növény. Több országban vörös listás, vörös könyves, veszélyeztetett faj (LUDWIG \& SCHNITTLER 1996, Strauch 1997, Holub \& ProcházKa 2000, Cheffings \& Farrell 2005, Dihoru \& Negrean 2009, GRULICH 2012), elterjedésének határterületein az 1970-es évektől drámai mértékű visszaszorulásáról tudósítanak (PRESTON et al. 2002, Kull et al. 2002). Ritkulása kapcsán a gyepkezelések megszűnése, ill. a terresztris eutrofizáció és az ezzel párhuzamos gyomosodás, cserjésedés az említett tényezők (WALKER \& ROBINSON 2011). A Bakonyalján megtalált populáció természetvédelmi helyzete jelenleg megnyugtatónak tűnik. A devecseri Széki-erdő hasonló rétekkel, változatos gyepeket őrző nyiladékokkal mozaikos élőhelyszerkezete jelenleg kiváló feltételeket biztosít a növény fennmaradásához. Ismereteink szerint az erdészet évente egyszer kaszálja a gyepet, de láthatóan csak részlegesen, sávokban. Problémát a kaszálatlan erdőszél felől a Solidago gigantea számottevőbb térnyerése, illetve a gyep benádasodása jelenthet, de ezek a veszélyeztető tényezők a jelenlegi kaszálási gyakoriság fenntartásával valószínűleg féken tarthatók. 


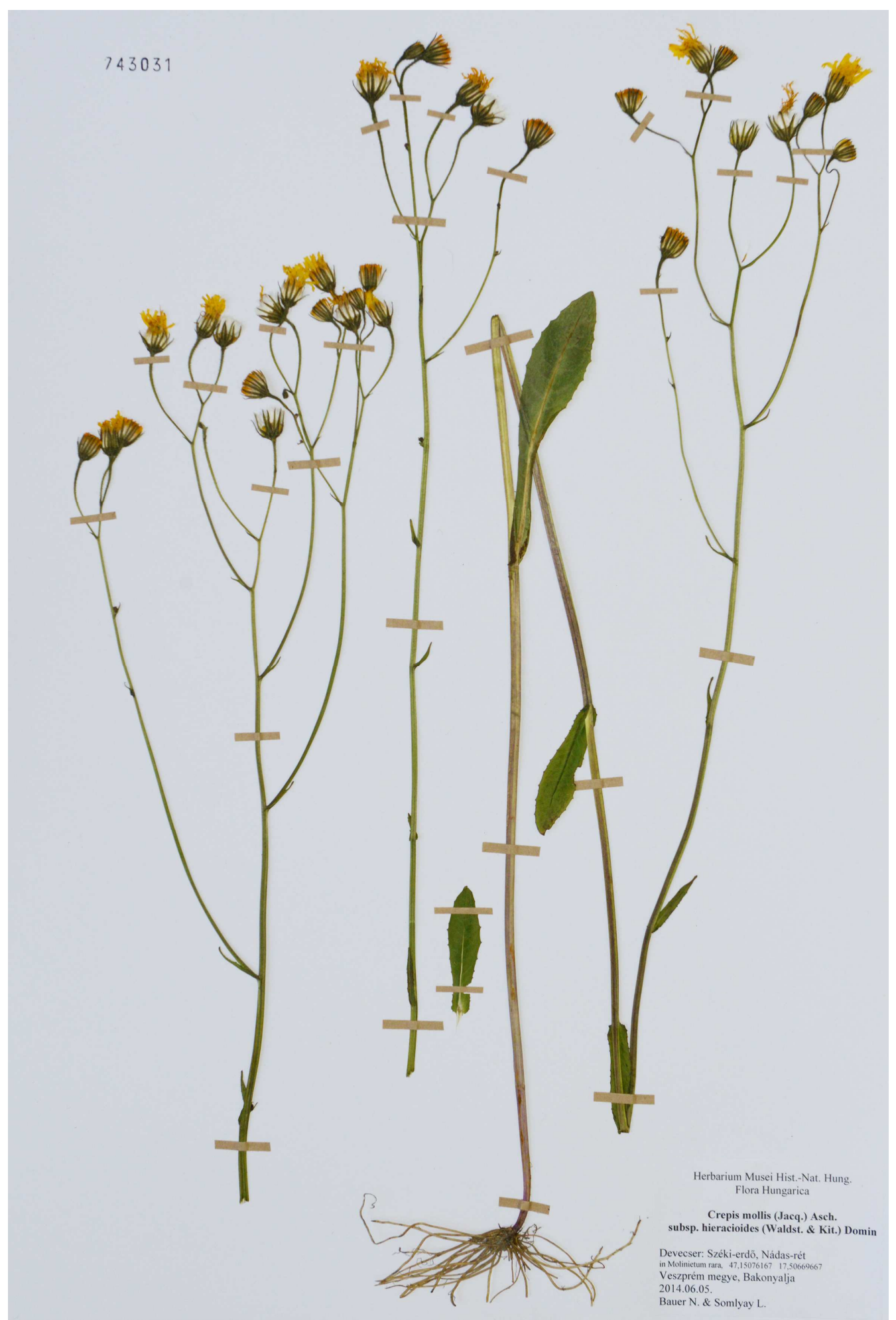

2. ábra. A Crepis mollis subsp. hieracioides devecseri bizonyítópéldánya (BP-743031). Fig. 2. Evidentiary specimen of Crepis mollis subsp. hieracioides (BP-743031) from Devecser, Bakonyalja. 153 
A Crepis mollis subsp. hieracioides meghatározását segítő, fontosabb bélyegek a következők: A szárlevél hosszúkás-visszás-tojásdad alakú, fényes-zöld, kopasz, ép, vagy kissé fogas szélű, válla lekerekített, ülő, legföljebb enyhén szíves vállal kissé szárölelő. Az alsó levelek hosszan nyélbe keskenyedők, a tőlevelek többsége virágzáskor már elszáradt. A szár a kocsány kivételével többnyire kopasz, végig leveles, 4-9(-18) fészkű. A fészek 2,5-3 cm széles, a külső fészekpikkelyek rásimulók, a külsők (3-4 mm) hossza legfeljebb fele a belsőkének (8-10 mm). A fészekörv és virágzati kocsány fekete szőröktől szőrös és mirigyes. A kaszat 3,5-4 mm hosszú, nem csőrös, a bóbita hófehér.

A taxon magyar nevének, PRISZTER (1998) nyomán, a lágylevelü zörgőfü elnevezést javasoljuk.

A Crepis mollis subsp. hieracioides-t ritkasága és növényföldrajzi jelentősége miatt Magyarországon indokolt lenne felvenni a védett és vörös listás fajok közé. Az IUCN kategóriarendszer besorolási kritériumait (GÄRDENFORS et al. 2001, IUCN 2001) figyelembe véve a növény magyarországi státusza kritikusan veszélyeztetett (CR /criteria: B1a/).

\section{Köszönetnyilvánítás}

Köszönjük Ingrid Turisová-nak (Banská Bystrica) a konzultációt és a szlovákiai szakirodalom beszerzésében nyújtott segítségét. A terepi kutatás a K 108992 számú, „Magyarország veszélyeztetett hajtásos növényeinek ritkasága, életmenet-jellemzői és klímaválasza” című OTKA pályázat támogatásával valósult meg. Molnár V. Attilának a kézirathoz füzött lektori javaslataiért mondunk köszönetet.

\section{Irodalom}

Allioni, C. (1785): Flora Pedemontana. Tomus primus. - Michele Briolo, Turin, 344 pp.

BАВсоск, E. B. (1947): The genus Crepis, part. two, Systematic Treatment. - University of California Publications in Botany 22. University of California Press, Berkeley \& Los Angeles, pp. 199-1030.

Balatova-Tulackova, E. (1996): Diversität der Nass und Feuchtwiesen der Ordnung Molinietalia in der Tschechischen und der Slowakischen Republik. - Acta Botanica Gallica 143: 299-307.

BAUER N. (2009a): Florisztikai adatok a Bakonyból és a Bakonyaljáról IV. - Kitaibelia 14: 16-29.

BAUER N. (2009b): Aconitum variegatum L. a Bakonyalján. - Kitaibelia 14: 107-108.

BlAŽKovÁ, D. \& CHYTRÝ, M. (2007): Polygono bistortae-Trisetion flavescentis Br.-Bl. et Tüxen ex Marschall 1947. - In: ChYтRÝ, M. (ed.), Vegetace České republiky 1. Travinná a keříčková vegetace, Academia, Praha, pp. 188-195.

Buchwald, R., Rath, A., Willen, M. \& Gigante, D. (2007): Improving the quality of NATURA 2000 meadows: the contribution of seed bank and hay transfer. - Fitosociologia 44 (2) suppl.1: 313-319.

Cheffings, C. \& Farrell, L. (2005): The Vascular Plant Red Data List for Great Britain. - Joint Nature Conservation Committee, Peterborough, Species Status 7: 1-116.

DierschKe, H. (1981): Syntaxonomische Gliederung der Bergwiesen Mitteleuropas (Polygono-Trisetion). Ber. Int. Symp. Vereinigung Vegetationsk. 1980, pp. 311-341.

Dihoru, G. \& NEgREAn, G. (2009): Cartea Roşie a plantelor vasculare din România. - Editura Academiei Române, București, 630 pp.

Domin, K. (1936): Plantarum čechoslovakiae enumeratio. - Preslia 13-15: 1-305.

DosTÁL, J. (1950): Kvétena ČSR. - Přirodovědecké nakladatalstvi, Praha, 2269 pp.

DosTÁL, J. (1989): Nová Květena ČSSR 2. - Academia Praha, pp. 765-1548.

ElLENBERG, H. (1996): Vegetation Mitteleuropas mit den Alpen. 5. Aufl. - Eugen Ulmer, Stuttgart, 1095 pp.

Gärdenfors, U., Hilton-TAYloR, C., Mace, G. M. \& RodríGuez, J. P. (2001): The applications of IUCN Red List criteria at regional level. - Conservation Biolology 15: 1206-1212.

Gomвocz E. (1945): Diaria itinerum Kitaibelii. Auf Grund originaler Tagebücher zusammengestellt I-II. Természettudományi Múzeum, Budapest, 1082 pp.

Greuter, W. (2006+): Compositae (pro parte majore). - In: Greuter, W. \& RaAb-Straube, E. von (eds), Compositae. Euro+Med Plantbase - the information resource for Euro-Mediterranean plant diversity. 
(http://ww2.bgbm.org/euroPlusMed/PTaxonDetailOccurrence.asp?NameId=7530955\&PTRefFk=7 000000) (Hozzáférés: 2015. 02. 24.)

Grulich, V. (2012): Red List of vascular plants of the Czech Republic: 3rd edition. - Preslia 84: 631-645.

Havlová, M. (2006) Syntaxonomical revision of the Molinion meadows in the Czech Republic. - Preslia 78: 87-101.

HegedüŠovÁ, K., Ruzicková, H., SEnko, D. \& ZucCARini, P. (2012): Plant communities of the montane mesophilous, grasslands (Polygono bistortae-Trisetion flavescentis alliance) in Central-Europe: Formalized classification and syntaxonomical revision. - Plant Biosystems 146: 58-73.

HENDRYCH, R. (1968): Flora Montium Muraniensium. - Acta Univ. Carolinae Biol.: 95-223.

Holub, J. \& ProcháZKa, F. (2000): Red List of vascular plants of the Czech Republic 2000. - Preslia 72 : 187-230.

HoRToвÁGYI T. (szerk.) (1955): Növényhatározó. Második kiadás. - Tankönyvkiadó, Budapest, 707 pp.

HundT, R. (1961): Die Bergwiesen des Harzes, Thüringer Waldes und Erzgebirges. - Jena, Pflanzensoziologie 14: 284 pp.

IUCN (2001): IUCN Red List categories and kriteria: version 3.1. - IUCN Species Survival Commission, Gland \& Cambridge (http://www.iucnredlist.org/technical-documents/categories-andcriteria/2001-categories-criteria) (Hozzáférés: 2015. 02. 24.)

JARоLímEк, I. \& Šiвíк, J. (2008): Diagnostic, constant and dominant species of the higher vegetation units of Slovakia. - Veda, Bratislava, 329 pp.

JávoRKA S. (1924-1925): Magyar Flóra (Flora Hungarica). - Studium, Budapest, 1307 pp.

JÁvorKA S. (1926): Kitaibel herbariuma. Herbarium Kitaibelianum. - Annales Musei Nationalis Hungarici 24: 428-585.

JávoRKA S. (1937): A magyar flóra kis határozója. Második, bővített kiadás. - Studium, Budapest, 346 pp.

JÁvorKa S. \& Soó R. (1951): A magyar növényvilág kézikönyve I-II. - Akadémiai Kiadó, Budapest, 1120 pp.

Kull, T., KuKK, T., Leht, M., KRAlL, H., KuKK, Ü., Kull, K. \& KuUSK, V. (2002): Distribution trends of rare vascular plant species in Estonia. - Biodiversity and Conservation 11: 171-196.

LudwiG, G. \& SchnitTler, M. (eds) (1996): Rote Liste gefährdeter Pflanzen Deutschlands. - Schr.R. f. Vegetationskunde 28: 744 pp.

MEuSEL, H. \& JäGER, E. J. (1992): Vergleichende Chorologie der zentraleuropäischen Flora. Band III. Karten - Gustav Fischer Verlag, Jena, Stuttgart, New York, part 1 (Text): 333 pp.; part 2 (Karten): 266 pp.

Meusel, H. \& NiemanN, E. (1971): Der Silgen-Stieleichenwald (Selino-Quercetum roboris). Struktur und pflanzengeographische Stellung. - Arch. Naturschutz u. Landschaftsforsch. 11: 203-233.

OBERDORFER, E. (1949): Pflanzensoziologische Excursionsflora für Südwestdeutschland und die angrenzende Gebiete. - Eugen Ulmer, Suttgart, $411 \mathrm{pp}$.

OndRejová, I., (1989): Rod Crepis L. na Slovensku. - Druhy horských a vysokohorských polôh. 162 pp. dipl. práca, ms. [Depon. in Knižnica Katedry botaniky PríF UK Bratislava]

PASSARGE, H. (1969): Zur soziologischen Gliederung mitteleurpäischer Frischwiesen. - Feddes Repertorium 80: 357-372.

PAWŁOWSKI, B., PAWŁOWSKA, S. \& ZARZYCKI, K. (1960): Zespoły roślinne kośnych lak pólnonej cześci Tatr i Podtatrza - Les associations végétales des praires fauchables de la partie septentrionale des Tartas et de la Region Subtatrique. - Fragmenta Floristica et Geobotanica 6: 95-222.

Penksza K. \& Szerdahelyi T. (2009): LXXVIII. Crepis L. - Zörgőfü. - In: KirÁly G. (szerk.), Új magyar füvészkönyv. Magyarország hajtásos növényei. Határozókulcsok. Aggteleki Nemzeti Park Igazgatóság, Jósvafő, pp. 451-452.

Preston, C. D., Pearman, D.A. \& Dines, T. (2002): New atlas of the British and Irish flora. - Oxford University Press, Oxford, $910 \mathrm{pp}$.

PriszTER Sz. (1998): Növényneveink. - Mezőgazda Kiadó, Budapest, 547 pp.

RÉDL R. (1942): A Bakony-hegység és környékének flórája. [Flora regionis montium Bakony] Egyházmegyei Könyvnyomda, Veszprém, Magyar Flóramúvek V. 157 pp.

RÖPERT, D. (ed.) (2000) [continuously updated]: Digital specimen images at the Herbarium Berolinense. Published at http://ww2.bgbm.org/herbarium/ (Barcode: B -W 14746 -01 0 / ImageId: 388258) (Hozzáférés: 2015. 02. 13.)

SCHNITTLER, M. \& GÜNTHER, K-F. (1999): Central European vascular plants requiring priority conservation measures - an analysis from national Red Lists and distribution maps. - Biodiversity and Conservation 8: 891-925. 
Simon T. (1992): A magyarországi edényes flóra határozója. Harasztok, virágos növények. Tankönyvkiadó, Budapest, $892 \mathrm{pp}$.

Soó R. \& KÁRPÁTI Z. (1968): Növényhatározó II. Harasztok - virágos növények. - Tankönyvkiadó, Budapest, 846 pp.

Soó R. (1970): A magyar flóra és vegetáció rendszertani növényföldrajzi kézikönyve IV. Synopsis systematico-geobotanica florae vegetationisque Hungariae IV. - Akadémiai Kiadó, Budapest, 614 pp.

STRAUCH, M. (1997): Rote Liste gefährdeter Farn- und Blütenpflanzen Oberösterreichs und Liste der einheimischen Farn- und Blütenpflanzen Oberösterreichs. - Beiträge zur Naturkunde Oberösterreichs 5: 3-63.

SZAFER, W., PAWŁoWski, B. \& Kulcziński, S. (1925): Zespoły roślin $w$ doline Kościeliskiej. Die Pflanzenassoziationen des Tatra-Gebirges III. Die Pflanzenassoziationen des Kościeliska-Tales. Bulletin de l'Académie Polonaise des Sciences et des Lettres (1925) pp. 13-78

TALLós P. (1959): Növényföldrajzi és florisztikai adatok a Dunántúlról. (Pflanzengeographische und floristische Beiträge aus Transdanubien) - Botanikai Közlemények 48: 77-80.

Turisová, I. (2002): Rod Crepis L. vo Vel'kej Fatre. - In: AlBerty R. (ed.), Rastlinstvo a živočíšstvo Vel'kej Fatry. Zborník referátov z vedeckej konferencie. Matthias Belivs Univ. Proc., Banská Bystrica, Suppl. 2 (1), pp. 77-89.

WalDSTEIN, F. A. \& KitAiBel, P. (1802): Descriptiones et Icones plantarum rariorum Hungariae Vol. I. Viennae, 104 pp. 100 Tab.

WALKER, K. \& RoBinson, L. (2011): Yorkshire's threatened plants: Northern Hawk's-beard Crepis mollis. Naturalist 136 Issue 1077, p. 90.

Beérkezett / received: 2015. 01. 30. • Elfogadva / accepted: 2015. 04. 01. 